\title{
Special feature: evolving diversity of firms and industries and dynamics of economic structures: the régulationist and institutionalist approach to Japan, South Korea, and Taiwan
}

\author{
Hiroyasu Uemura ${ }^{1}$ Yuji Harada ${ }^{2}$
}

Published online: 2 June 2016

(C) Japan Association for Evolutionary Economics 2016

The régulation theory, established in the mid-1970s, has influenced various kinds of evolutionary and institutional political economy. On the 40-year anniversary of the régulation theory, the International Conference Research and Régulation 2015: The Theory of Régulation in Times of Crises was held June 9-12, 2015, at the Université Paris-Diderot in Paris. In this special issue, we have collected some of the best articles on Asian capitalism which were presented at the international conference in Paris.

In the epoch-making conference, some new perspectives were presented to develop the régulation theory. For example, the importance of the meso-level analysis, which includes firms and industries, and of multi-level time and space is emphasized to develop the theoretical framework of the régulation theory. In fact, the analyses of the evolving diversity of firms and industries and the dynamics of structural change with multi-level structures of the time horizon have been developed recently.

The analysis of the diversity of Asian capitalisms has been developed very actively in the framework of the régulation theory. Of special note, Diversity and Transformation of Asian Capitalisms [Robert Boyer, Hiroyasu Uemura, Akinori Isogai (eds.), Routledge, 2012] was published as a productive result of international collaborative research. Based on this achievement, many studies have begun

Hiroyasu Uemura

huemura@ynu.ac.jp

Yuji Harada

y-harada@fcu.ac.jp

1 Graduate School of International Social Sciences, Yokohama National University,

79-4 Tokiwadai, Hodogaya-ku, Yokohama 240-8501, Japan

2 Faculty of Urban Management, Fukuyama City University, 2-19-1 Minato-machi, Fukuyama 721-0964, Japan 
analyzing Asian capitalisms, taking into account the meso-level structures of institutional changes in the development of globalization. In particular, the contributors to this special issue focus on firm organizations and corporate governance, productive systems, industrial structural changes, economy-environment relations, and the diversity of the innovation systems and capitalism in Japan, South Korea, and Taiwan as well as other East Asian countries.

Mitsuharu Miyamato, in his article "Diversification of Japanese Firms: How Hybrid Organizations Evolved Through Corporate Governance Reform," analyzes the diversification of Japanese firms. Confronted with the critical business situation in the late 1990s, Japanese firms initiated two kinds of corporate reform: corporate governance and human resource management reforms. Japanese firms seemed to change from organization-based to market-based corporations by adopting the USstyle shareholder-oriented corporate governance. However, the actual change was not an overall transformation, but rather was incremental and cumulative. The article focuses on management reform through the introduction of the corporate executive officer system and examines the resulting changes in human resource practices. In particular, Miyamoto finds a new type of organization that introduces performance-related pay while maintaining long-term employment and another type of organization, which introduces performance-related pay and discourages longterm employment. This study investigates the evolutionary process of diversification in Japanese firms, using two sets of individual data that cover the ongoing changes in corporate governance and human resource management.

Mayumi Tabata, in her article "The Collapse of Japanese Companyist Regulation Survival of the Upstream Industry: Developing East Asian Production Linkage," shows that the Japanese downstream industries, such as the consumer electronics industry, face fierce competition owing to the catch-up phenomenon prevalent among South Korean, Taiwanese, and Chinese manufacturers, and that the Japanese industries transform themselves. Many factories of Japanese consumer electronics firms were forced to shut down. Furthermore, upstream Japanese firms such as electronic component and equipment suppliers have lost their business in the Japanese domestic market and have been forced to enter global markets. In particular, with regard to the Japanese upstream industry and Taiwanese thin-film transistor liquid crystal display (TFT-LCD) downstream firms, the Japanese electronic component and equipment suppliers have been integrated into the strategic production linkages in East Asia. They are increasingly abandoning Japanese clients to become the main electronic component and equipment suppliers for TFT-LCD manufacturers in Taiwan. In this regard, Japanese upstream firms have maintained their technological advantages in the global TFT-LCD markets and continue to dominate the electronic component and equipment business for TFT-LCD manufacturers in Taiwan.

Wooseok Ok, in his article "The Korean Exception: Service Outsourcing by Manufacturing Firms and the Role of Institutions," elucidates the specificity of deindustrialization in Korea. Although the share of manufacturing in terms of employment has increased, that of value added remains almost unchanged. The contradictory changes are specific to the Korean economy. The article examines the determining factor of de-industrialization in Korea, focusing on the increase in service intermediate outsourcing. In the Korean case, service outsourcing, measured 
by the number of employed persons in the service industries that supply service intermediates to the manufacturing industry, implies a substitution of intermediate inputs in the production process. This can occur even though the shift of final demand does not exist. Internationalization, which is calculated as the number of job loss in the manufacturing industry due to international trade, indicates the shift between domestic production for external demand and foreign production for domestic demand. Both of them can be recognized as the demand effect. Furthermore, it is pointed out that service intermediate outsourcing, identified as the principal factor in the de-industrialization process, has a negative productivity effect. The technologies in outsourced service intermediates become more and more labor-intensive. In addition, the workers who engage in outsourced service intermediates became less skill-intensive. These specificities of the Korean deindustrialization process rely on its manufacturing firms' motivation for cost savings and pursuit of higher flexibility. ${ }^{1}$

Hiroshi Nishi, in his article "Structural Change and Transformation of Growth Regime in the Japanese Economy," investigates the growth process in Japan since the 1970s. First, the article clarifies several types of structural changes in the growth process by calculating some indicators of structural change, using the Japan Industrial Productivity (JIP) database. The speed of structural change in value added increased since the late 1990s. As for the structural changes in labor and capital-labor ratio, no definite trend is found. Second, value added and labor productivity are decomposed by using the indicator of log variance to measure the change in the sectoral dispersion of economic performance. The dispersion among sectors regarding both variables decreased until the 1990s but increased from the 2000s. Third, using the method of Harberger's sunrise-sunset diagram, Nishi shows that sectoral contribution aggregates growth in value added and labor productivity. The result of analysis indicates a pattern of sectoral contribution changes between the pre- and post-1990 periods: an even growth process in the 1970s and 1980s, and an uneven growth process in the 1990s and 2000s. Fourth, by estimating the growth rates of real value added and labor productivity by the indicators of structural change computed in the previous section, it is pointed out that the structural change in output has a stronger impact on economic growth than that in inputs. However, the strength of the impact has weakened since the 1990s. Therefore, the growth regime before the 1990s can be characterized as that with decreasing heterogeneity and relatively uniform growth at the sector level. The growth regime after the 1990s can be characterized as that with increasing heterogeneity and uneven growth among sectors. Furthermore, the sectoral heterogeneity remains, hence the growth regime cannot be sufficiently steady in the 2000s.

Kazuhiro Okuma, in his article "Long-Term Transformation of the EconomyEnvironment Nexus in Japan: a Historical Analysis of Environment Institutions and Growth Regimes Based on the Régulation Theory," proposes a theoretical

\footnotetext{
1 The patterns of de-industrialization are similar in Korea and Japan as the externalization of service activities and workers from the manufacturing industry to the service industry has been remarkable in both economies recently. As for de-industrialization in the Japanese economy, see Hiroyasu Uemura and Shinji Tahara, "The Transformation of Growth Regime and De-industrialization in Japan," Revue de la régulation, No. 15, 2014. However, the negative productivity effect of service outsourcing, which is pointed out in Ok's article, is very specific to the de-industrialization process in the Korean economy.
} 
framework to analyze the relationship between environmental policies and economic growth based on the régulation theory. To advance the research with this approach, Okuma conducts a historical analysis of the economy-environment nexus which is one of the "institutional forms" in the régulation theory. Environmental costs are estimated as key indices. An econometric analysis is conducted to analyze the effects on the growth regime in the Kaleckian growth model. Based on the empirical analysis, the author periodizes and specifies the economy-environment nexus in Japan, which included (1) the 1960s to around 1970, with intensive accumulation complemented by extensive consumption of environment resources; (2) the 1970s to the early 1980s, with strict regulations formulated through social conflicts, which were supportive to growth; (3) the 1990s to early 2000s, with some institutions of voluntary and flexible nature with weaker actors; and (4) after 2008, with some policies aiming at green growth as a common agenda of economic and environmental actors.

Hironori Tohyama and Yuji Harada, in their article "Diversity of Institutional Architectures Underlying the Technological System in Asian Economies," attempt to clarify the specificity of Asian economies and the diversity in these economies from a perspective of international comparison. They assume the technological system, which is the linkage among science, technology, and industry in line with the literature, as an intermediary between institutions and economic performance. Moreover, their findings supplement some of the institutional domains such as "state," "social capital," and "international regime" in order to more adequately deal with the diversity of Asian technological systems and their institutional configurations. On conducting statistical analyses, they find that Asian economies are differentiated from advanced economies in terms of technological systems as well as institutional architectures. One of the common characteristics in Asian economies is that the institutional domain of "state" has a prominent role as a focal point binding other domains to support technological systems. Tohyama and Harada also distinguish six clusters of technological architecture, which are similar to the institutional diversity of Asian economies as was verified by Harada and Tohyama $(2012)^{2}$. In their article in this special issue they imply that multiple institutional architectures promoting the technological system in Asian economies could present them for multiple pathways to reach the technological frontier.

The régulation theory is a very open and promising research program of institutional and macroeconomic analyses that has wide room for further development at different levels of economic structures and institutional changes of the varieties of capitalism in the globalized world. In this context, various international collaborative studies have started analyzing the evolving diversity and interdependence of Asian capitalisms ${ }^{3}$.

\footnotetext{
${ }^{2}$ Yuji Harada and Hironori Tohyama (2012) "Asian capitalisms: institutional configurations and firm heterogeneity," in Boyer R, Isogai A, Uemura H (eds.) Diversity and Transformations of Asian Capitalisms, Routledge, pp. 243-263.

${ }^{3}$ In the recent development of the régulation theory, Robert Boyer has formalized the theoretical framework of the different levels of régulation (national, local, supernational, and global) and interactions between polity and economy in a systematic way. See Robert Boyer, Économie politique des capitalismes: Théorie de la régulation et des crises, La Découverte, 2015.
} 